\title{
NDE of frescoes by infrared thermography and lateral heating
}

\author{
by E. Grinzato ${ }^{1}$, P. G. Bison ${ }^{1}$, C. Bressan ${ }^{1}$ and A. Mazzoldi ${ }^{2}$ \\ ${ }^{1}$ Consiglio Nazionale delle Ricerche - ITEF, corso Stati Uniti 4, 35127 Padova, Italy \\ ${ }^{2}$ Consiglio Nazionale delle Ricerche - ISDGM, San Polo 1364, 30125 Venezia, Italy
}

\begin{abstract}
The lateral heating procedure is applied to frescoes. A dedicated algorithm is proposed to reconstruct conventional thermograms and to identify detachments of the plaster and cracks. Then a map of defect location and extension is produced. Two numerical models have been implemented to simulate tests. A prototype equipment was also developed and applied both in laboratory and in situ.
\end{abstract}

\section{Introduction}

IR thermography is a well known method for Non-Destructive Testing (NDT) of works of art and particularly frescoes. Recently, the use of dynamic techniques and quantitative processing of data has allowed a significant increase in the reliability of findings. However, as the absorption coefficient of paint varies on the surface, false alarms may be produced when the fresco is thermally stimulated by absorption of radiation. In order to reduce this problem a shift of the spectrum emitted by the heat sources towards IR is proposed. Another problem related to the dynamic approach is the very long inspection time due to the low thermal diffusivity of the plaster. This is particularly important when large surfaces must be tested so that a mosaic has to be composed from individual areas.

Starting from the flying spot or box car technique [1-3] the lateral heating has been introduced to detect cracks. In a previous work [4] the tuning of the procedure, taking into account the low thermal diffusivity of plaster, has been investigated. Some authors applied the lateral heating of structures with a linear lamp in order to increase the very low productivity of the flying spot technique [5-8]. The use of a convective heat source at laboratory stage was also suggested [9] to get rid of the absorptivity variation in colored surfaces. In the present work this technique is used to detect in the same experiment two kinds of defect: the detachment of the painted layer and cracks.

The use of thermal models allows to fit at the best the tight requirements related to the inspection of frescoes. The problem of modeling the temperature pattern due to a vertical crack is specially stressed in this work.

\section{Description of the algorithm and thermal model of a moving line source}

A linear motion of the source at constant speed is adopted to reach a uniform stimulation of the fresco and to avoid disturbance of side testing. Of course, the maximum temperature on the surface is reached at different time. Therefore, the following algorithm is proposed to reconstruct images. Let us consider the heat source moving from left to right in the camera field of view. A set of new images is generated sampling and stacking in a matrix the same row in each successive image of the sequence. A tilted warm line appears on any synthetic image representing the maximum heating (MHL) of any pixel. Of course the slope of the $\mathrm{MHL}$ depends on the source velocity, the sampling time, and the field of view of the IR camera. Each line parallel to $\mathrm{MHL}$ is isochrone, incorporating pixels having the same time of occurrence in the thermal process. This corresponds to the usual set-up when the IR sensor and the heat source are linked at a fixed offset. The distance between parallel lines characterises the time delay. Finally, the composition of all the lines produces the searched isochronous thermogram, that is corresponding to a particular time delay referred to the heating. 
A model of the thermal problem allows to choose the source speed, to predict the correct time delay in the inspection, and to control the maximum temperature increase on the very sensitive surface of the fresco. Two different models of the layered target have been developed. Both of them are suitable for the considered defect type and yields also to inversion functions to estimate the depth of delaminations. The temperature pattern of the surface, caused by the detachment of the plaster layer (thickness $25 \mathrm{~mm}$ ) from the bearing brick wall (thickness $500 \mathrm{~mm}$ ), is predicted by a finite element 2D numerical model. Such a model was implemented in the Matlab ${ }^{\mathrm{m}}$ environment. An air filled defect (thickness $5 \mathrm{~mm}$ ) was placed at depths of 5,15 and $25 \mathrm{~mm}$. The thermal properties assumed for the materials are: a) plaster density $\rho=1440 \mathrm{~kg} \mathrm{~m}^{-3}$, specific heat $c_{p}=840 \mathrm{~J} \mathrm{~kg}^{-1} \mathrm{~K}^{-1}$, conductivity $\lambda=0.48 \mathrm{~W}$ $\mathrm{m} \mathrm{K}^{-1}$; b) brick wall $\rho=1600, c_{p}=840, \lambda=0.69 ; \mathrm{c}$ ) air $\rho=1.2, c_{p}=700, \lambda=0.03$. To simulate the surface heating with a moving heat source from left to right, a Gaussian function with a full width at half maximum (FWHM) of $30 \mathrm{~mm}$ and moving with a velocity $v=0.025 \mathrm{~m} \mathrm{~s}^{-1}$ was used in a similar way presented by Lehtiniemi et al.[10]. The boundary conditions on the front assume a convective coefficient $h=10 \mathrm{~W} \mathrm{~m}^{-2} \mathrm{~K}^{-1}$, other surfaces are adiabatic. Fig. 1a collects in an image the computed temperature profile for each point (node of the grid) of the surface. The gray level expresses the temperature. A distortion in the cooling stage (due to the defect) is evident in the centre of the image. Fig. 1b shows 3 profiles of temperature signals corresponding to the three simulated defects.

The behavior of a crack is simulated by a model leading to a closed analytical solution [11]. We assume as a starting point that the medium is semi-infinite and moving along the $x$ direction under the source of heat fixed in the $x=0$ position. The source which is infinite along the $y$ direction has a finite dimension along $x(-b<x<b)$, delivering heat at a rate $q$. The vertical crack is located at $x_{c}$ and represents an ideal infinite thermal resistance (see Fig. 2a). In the steady regime the solution is time-independent and is accounted by the following formula:

$$
T(X)=\frac{2 \alpha q}{\pi \lambda v} \int_{x-B}^{x+B} e^{u} K_{o}(|u|) d u
$$

where $\alpha$ is the thermal diffusivity of the material; $X=x v / 2 \alpha$ and $B=b v / 2 \alpha$ are dimensionless spatial coordinate and extension of lamps, respectively; $K_{0}$ is the modified Bessel function of zero order. Fig. $2 \mathrm{~b}$ shows some typical temperature profiles for the adopted model with $\alpha=3.9610^{-7} \mathrm{~m}^{2} \mathrm{~s}^{-1} \lambda=0.48 \mathrm{~W} \mathrm{~m}^{-1} \mathrm{~K}^{-1}, q=15000 \mathrm{~W} \mathrm{~m} \mathrm{~m}^{-2}$. The three curves correspond to $v=0.025,0.05,0.1 \mathrm{~m} \mathrm{~s}^{-1}$ from the highest to lowest respectively, while $x= \pm b= \pm 0.045 \mathrm{~m}$ correspond to the lamp borders and to an abrupt change of temperature slope. The image source principle is adopted for crack simulation. Assuming that no heat is passing through the crack, we model the actual temperature as due to the real source plus a second fictitious one, located symmetrically with respect to the crack. Results for different heat source velocities are given in fig. $2 \mathrm{c}$ where $x$ represents the crack coordinate, while the IR sensor is positioned immediately after the end of the lamp $\left(x_{d}=0.045 \mathrm{~m}\right)$. When the crack is far from the detector, a constant temperature is obtained, while an increase is observed as the crack approaches the probe position. Of course, when the crack overcomes the probe position, a symmetric negative peak appears. This means that in any interval centered on the detector position, the average value of the temperature must be constant as it is the delivered energy.

\section{Experimental results}

A dedicated equipment was set up in order to stimulate the surface, while a hermographic equipment (Agema ${ }^{\mathrm{TM}} 900 \mathrm{LW}, 8-14 \mu \mathrm{m}$ ) stored a sequence of thermograms in digital format $272 \times 136$ pixels with a resolution of $12 \mathrm{bit} / \mathrm{pixel}$. The radiation of a linear lamp ( $3000 \mathrm{~W}$ electrical power, $700 \mathrm{~mm}$ long) was focused on a strip at a distance of $30 \mathrm{~mm}$. The nominal $400 \mathrm{~V}$ voltage supply was reduced to $220 \mathrm{~V}$ in order to shift the irradiated wavelength towards the IR band thereby reducing differences in the energy absorption. The equipment 
was placed on a motorized rail controlled trough an inverter. The surface was scanned by the source at a constant speed in the range from 0.017 to $0.1 \mathrm{~m} \mathrm{~s}^{-1}$. A preliminary version of the equipment is shown in fig. 3 a during former tests.

The procedure and the equipment were tested on a segment of wall covered with unpainted plaster containing artificial defects at known positions. This specimen simulating an ancient wall was manufactured by a specialized workshop. During the heating a faster data acquisition was chosen and the process lasted from 10 to $60 \mathrm{~s}$, depending on the source speed. Then the source was switched off and the still IR camera slows down the acquisition rate, grabbing images for another $1000 \mathrm{~s}$. Fig. $3 \mathrm{~b}$ shows the isochronous image reconstructed from the sequence, as it were heated at the same time. A modified version of the thermal tomography algorithm [12,13] was applied. Fig. 3c shows the normalized thermal contrast profiles versus time for detached zones in depths of $8,12,15$ and $20 \mathrm{~mm}$, respectively. Finally fig. 3d illustrates the tomogram of defects at $12 \mathrm{~mm}$ depth.

A second set of experiments involves three samples of frescos containing both detachments and a crack (see fig. 4a). Fig. $4 b$ exhibits the map of thermal signal amplitude when the source moves at $0.025 \mathrm{~m} \mathrm{~s}^{-1}$. The crack and an underlying detachment are well seen in the middle of the central specimen. Fig. 4c explains how results have been produced. For example, the line marked on fig. $4 \mathrm{a}$ is examined along the thermograms sequence, and the stack along time of this row is shown in the upper part of fig. 4c. The lower part of the same picture reveals an isochronous thermal profile that is drawn along the tilted line parallel to the MHL after the heating. The footprint of a crack is visible in the middle of the profile. Of course, the same characteristic signals are also produced at any edge of the three samples. In principle, similar results could be obtained also before the heating, but it was theoretically found that this requires a much slower speed of the source. It is worth noticing the similarity of this picture with the simulated results of fig. 1a. Finally, all isochronous profiles are composed giving an isochronous thermogram.

The last experiment was performed under control of the cultural heritage supervisor, inside the "Palazzo della Ragione" hall, a historical building at Padova, frescoed during the Renaissance age. The whole fresco is more than $1000 \mathrm{~m}^{2}$ rising up to a height of $10 \mathrm{~m}$. To overcome some practical problems the second prototype shown in fig. 5 was set up. Fig. $6 a$ shows a raw thermogram of an area of approximately $4 \mathrm{~m}^{2}$ taken after the complete scanning by the heat source. In this zone both two cracks and a large detachment were found and confirmed by restaurateurs. These results are depicted in fig. $6 \mathrm{~b}$ obtained according to the modified version of the thermal tomography algorithm.

\section{Conclusions}

The method proposed to monitor frescoes using a linear lateral heating was tested both in laboratory and in situ. Experimental results are in agreement with theoretical ones but a significantly higher value of thermal diffusivity of the plaster is suspected. In fact, an earlier thermal response is generally measured, if compared with results of the thermal model. Special efforts were spent to model the surface temperature due to a vertical crack.

A main problem arises under the specific reconstruction procedure that makes isochronous images. A high frequency noise appears, particularly, when the image at maximum heating is reconstructed in order to normalize the contrast, due to the sampling process of any digital image. This introduces vertical fringes as artifact. A development of the procedure is going on in order to solve such a problem and to speed up the inspection.

\section{Acknowledgments}

The authors acknowledge contribution of Mr. E. Arlango, the Community of Padova for the permission to test the fresco and to the CNR-P.F. "Cultural Heritage" for the financial support. 


\section{REFERENCES}

[1] GRUSS (C.) and BALAGEAS (D.) - Theoretical and experimental applications of the flying spot camera. QIRT 92 - Eurotherm Series 27 - EETI ed., Paris 1992, p. 19-24.

[2] KUBIAK (E. J.) - Appl. Opt.7, 1968, p. 1743.

[3] AHMED (T.), FENG (Z. J.), KUO (P. K.), HARTIKAINEN (J.) and JAARINEN (J.) J. Nondestr. Eval. 6, 1987, 169.

[4] BISON (P. G.), GRINZATO (E.), BRAGGIOTTI (A.), MAZZOLDI (A.) and VAVILOV (V.) Non destructive evaluation of cracks in porous building materials by use of crawling spot technique. Review of Progress in QNDE, Vol. 15, Plenum Press, New York, 1996, p. 1895-1901.

[5] MALDAGUE (X.) - Nondestructive Evaluation of Materials by Infrared Thermography. Springer-Verlag, London, 1993.

[6] GREEN (D. R.), SCHMELLER (M. D.) AND SULIT (R. A.) - Proceedings of the $10^{\text {th }}$ international Thermal Spraying Conference, Deutscher Verband für Schweisstechnik. Dussendorf, 1983, p. 24.

[7] HARTIKAINEN (J.) - Rev. Sci. Instrum. 60, 1989, p. 670.

[8] CRAMER (K. E.), WINFREE (W. P.), HOWELL (P. A.) and SYED (H.) - Thermographic Imaging of Cracks in Thin Metal Sheets. SPIE Vol. 1682 Thermosense XIV, 1992, p. 162170.

[9] BISON (P. G.), GRINZATO (E.), MARINETTI (S.) and BRAGGIOTTI (A.) - Fresco thermographic inspection by convective heating technique. Rev. of Progr. in QNDE, Vol. 17, Ed. Thompson \& Chimenti, Plenum Press, New York 1998, p. 1769-1776.

[10] LEHTINIEMI (R.), RANTALA (J.) AND HARTIKAINEN (J.) - A photothermal line scanning system for NDT of plasma-sprayed coatings of nuclear power plant components. Res. Nondestr. Eval. 6, 1995, p. 99-123.

[11] CARSLAW (H. S.) and JAEGER (J. C.) - Conduction of heat in solids. Oxford at the Clarendon Press, 1959, p. 267-269.

[12] VAVILOV (V.) - Dynamic thermal tomography: perspective field of thermal NDT. SPIE Vol. 1313 Thermosense XII, 1990, p. 178-182.

[13] VAVILOV (V.), BISON (P. G.), BRESSAN (C.), GRINZATO (E.) and MARINETTI (S.) Some new ideas in dynamic thermal tomography. QIRT92 - Eurotherm Series 27 - EETI ed., Paris, 1992, p. 259. 


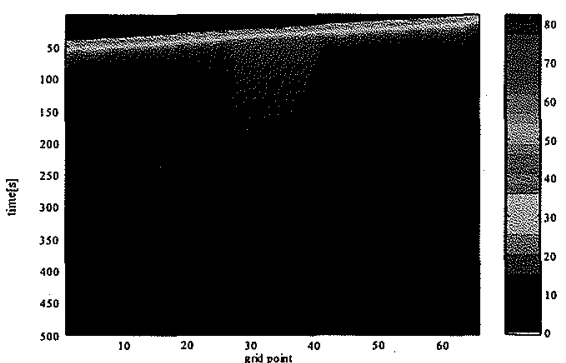

Fig. 1a. Numerical simulation of the surface temperature over a delamination

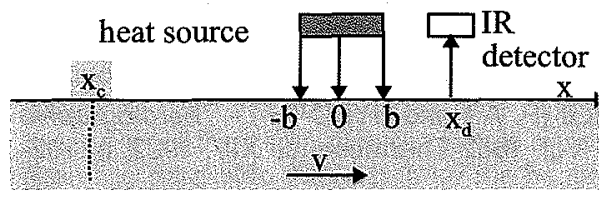

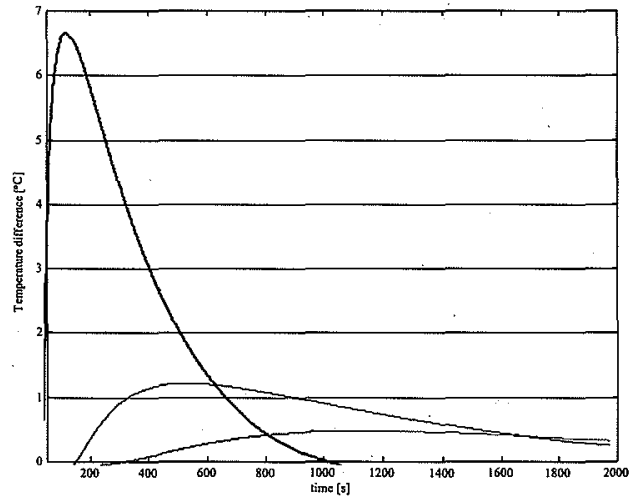

Fig. 1b. Temperature difference compared to sound material corresponding to 3 different delaminations

(depths 5, 15, and $25 \mathrm{~mm}$ from the highest to the lowest respectively)

Fig. 2a. Sketch of the testing procedure for crack identification

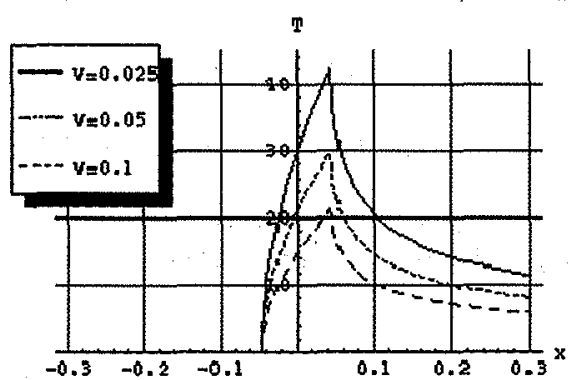

Fig. 2b. Temperature profiles as a function of the $x[\mathrm{~m}]$ coordinate

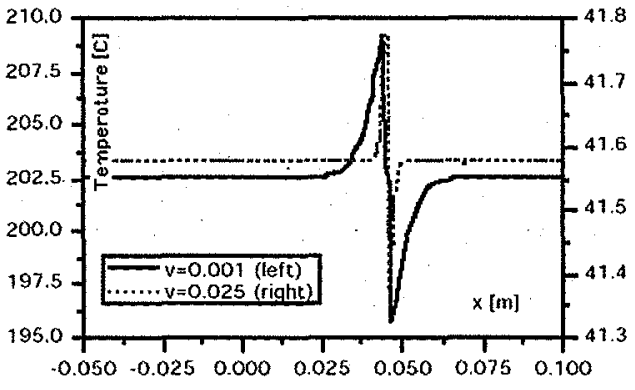

Fig. 2c. Curves representing temperature as a function of crack (velocity 0.025 and $0.001 \mathrm{~m} \mathrm{~s}^{-1}$ ) position 


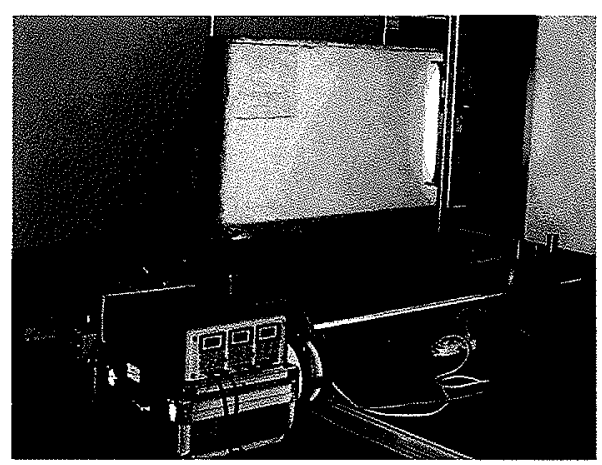

Fig. 3a. Early version of the experimental set up at laboratory and the used specimen of an ancient unpainted wall

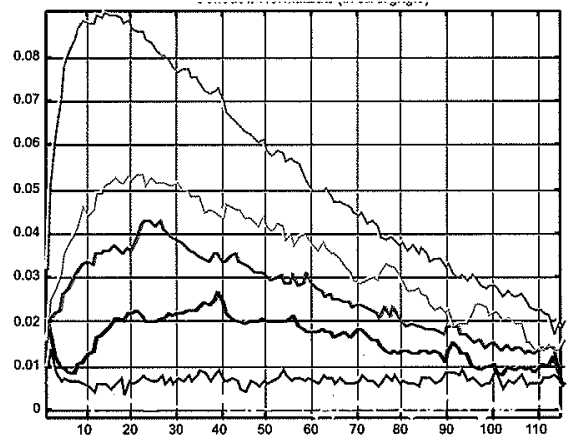

defects depth $8 \mathrm{~mm}, 12 \mathrm{~mm} 15 \mathrm{~mm} 20 \mathrm{~mm}$ ND

Fig. 3c. Experimental thermal contrast profile vs. time [s/10] for defects located at different depths

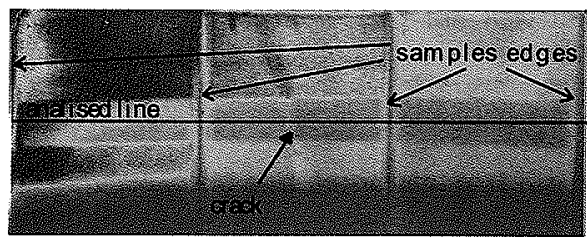

Fig. 4a. Row thermal image of 3 specimens reproducing a fresco a few minutes after end of heating

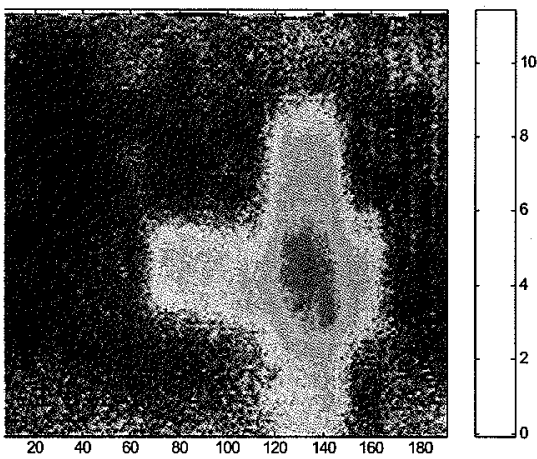

Fig. 3b. Reconstructed isochronous surface temperature on a plaster detachment after heating with a linear lamp at a speed $0.03 \mathrm{~m} \mathrm{~s}^{-1}$

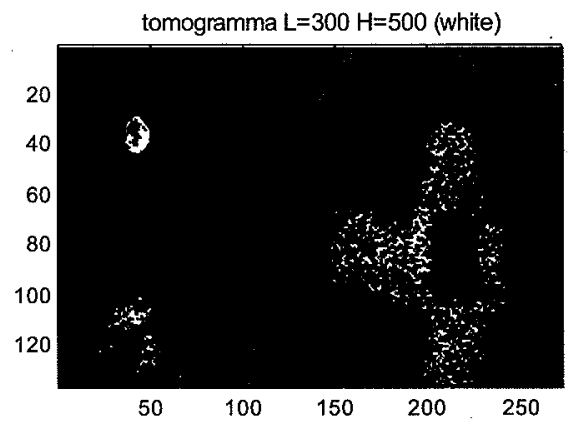

Fig. 3d. Thermal tomography of an artificial detachment at $12 \mathrm{~mm}$ depth by lateral heating

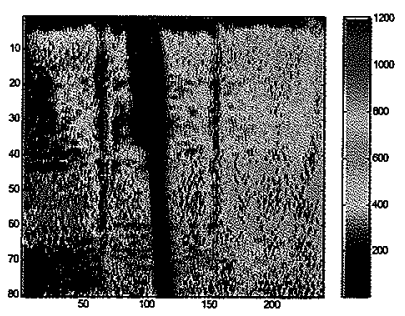

Fig. 4b. Maxigram related to the specimen of fig. 4a obtained at a speed of $0.025 \mathrm{~m} \mathrm{~s}^{-1}$ 
http://dx.doi.org/10.21611/qirt.1998.008

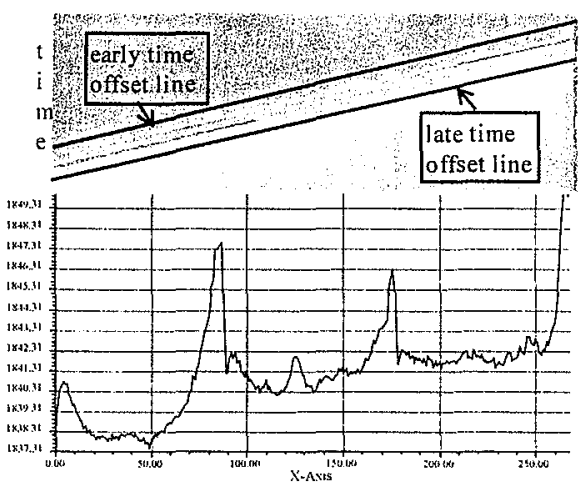

Fig. 4c. Image produced stacking the line of fig. $4 a$ for the crack identification $\left(v=0.025 \mathrm{~m} \mathrm{~s}^{-1}\right.$ ). Thermal signal corresponding to the "late time line"

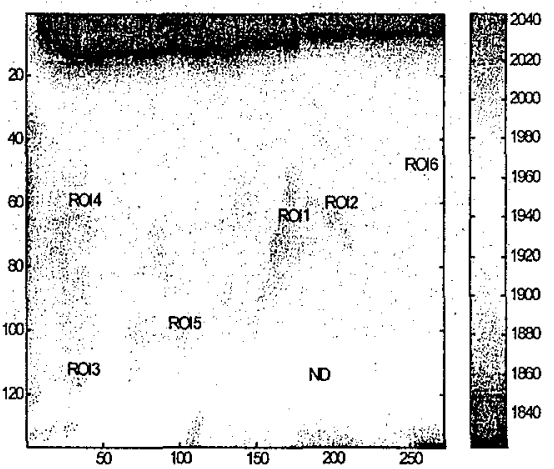

Fig. 6a. Inspection of a fresco in situ, row thermogram after the heating

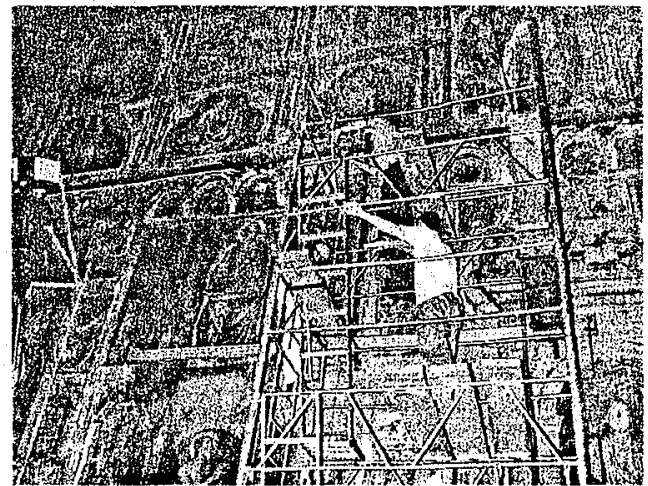

Fig. 5. View of the upgraded experimental set up during a test in situ

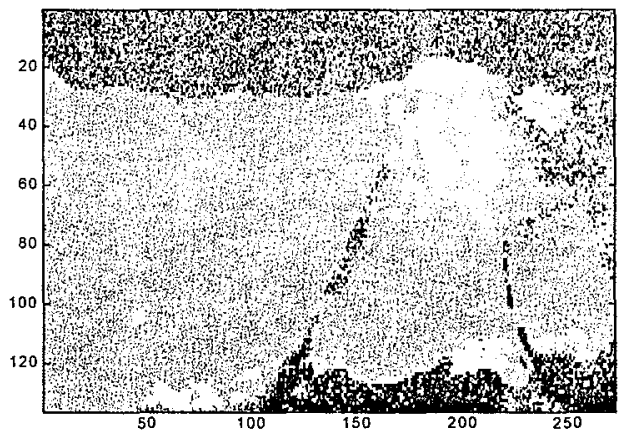

Fig. 6b. Results of the TNDT "tomogram", the gray levels different from the background indicates defects at different depth or cracks 